\title{
REDUÇĀO NA CONCENTRAÇÃO DE GLICOSE NO CÉREBRO DE CAMUNDONGOS INOCULADOS COM LIQUIDO CEFALORRAQUIANO DE PACIENTES COM ESCLEROSE LATERAL AMIOTRÓFICA
}

\author{
J.M. GODOY*-M. SKACEL * - J.M.B. LIMA***-C.M. ANDRADE****
}

RESUMO - Os autores analisam, por técnica cromatográfica, as concentraçōes de glicose no cérebro de camundongos inoculados com LCR de 4 pacientes com ELA. Foi encontrada redução na concentração do carboidrato no material estudado, sugerindo a presença de fator extrinseco veiculado pelo LCR.

Reduction in levels of glucose in the brain of mice inoculated with CSF of patients with amyotrophic Iatral sclerosis.

SUMMARY - Using chromatographic analysis the authors studied glucose concentration in the brain of Swiss mice inoculated with CSF of four patients with amyotrophic lateral sclerosis. They found reduction in the levels of glucose, suggesting the existence of an exogenous factor transfered by CSF.

Doença do neurônio motor (DNM) constitui grupo de enfermidades bem caracterizadas do ponto de vista clínico. Não obstante certas discordâncias quanto aos limites nosológicos, a esclerose lateral amiotrófica (ELA), sendo a entidade mais importante do grupo, confunde-se, costumeiramente, com este. Apesar da relativa facilidade na realização de seu diagnóstico, os fatores desencadeadores e seu mecanismo etiopatogênico permanecem desconhecidos. Essa falha de conhecimento básico se reflete na falta de qualquer tratamento racional para a DNM. A despeito da existência de variantes infantis 25 , juvenis 11 , familiares 4 e regionais 6 , a DNM é caracteristicamente doença do adulto, com predileçäo pelo sexo masculino e atingindo, com maior frequêencia, pessoas a partir da quinta década de vida. Entretanto, os autores têm observado dramática redução na faixa etária dos enfermos na cidade do Rio de Janeiro. Nas últimas décadas, busca-se, incessantemente, a causa da DNM. Seguindo a linha de raciocínio defendida por Kurland,citado por Müller e Hilgenstock 21 e de outros autores 24,31 , a DNM seria um «complexo sindrômico» de múltiplas etiologias possíveis. São as variantes esporádicas, citadas por Emery e Holloway 4 , yue poderiam ser provocadas por mecanismos distintos 20: infecçōes virais lentas; distúrbios endócrinos, metabólicos ou tóxicos; fenômenos imunológicos, para citar os mais importantes.

Levando-se em conta o poder de «sedução» da etiologia viral da ELA, neste estudo são analisadas as concentrações de glicose no cérebro de camundongos inoculados com líquido cefalorraquidiano (LCR) de 4 pacientes com a doença.

Trabalho sealizado no Departamento de Microbiologia da Universidade Federal do Rio de Janeiro (UFRJ): * Professor Adjunto de Neurologia da Universidade do Estado do Rio de Janeiro (UERJ); ** Professor Assistente de Neurologia da UERJ; *** Professor Adjunto de Neurologia da UFRJ; **** Professor Titular de Microbiologia da UFRJ. 


\section{MATERIAL E METODOS}

I. MATERIAL - (A) LCR: Foram colhidas amostras de LCR de 4 pacientes com diagnóstico de FLA e acompanhados no Instituto de Neurologia Deolindo Couto (INDC-UFRJ). As referidas amostras foram diluidas em solução salina fosfatada (PBS) $\mapsto$ classificadas conforme se segue: SCM, registro no INDC 48710 (Solucăo P1): CSR, registro no INDC 52732 (Solução P2); I.MA, registro no INDC 49611 (Soluçāo P3); JMPE, registro no INDC 50230 (Solução P4). (B) Animais: Foram utilizados 21 lotes de 6 camundongos suíços brancos, recém-nascidos, procedentes do biotério do Centro Pan-Americano de Febre Aftosa (RJ). (C) Soluçōes: A soluçāo de PBS foi preparada com a seguinte composiçāo: $\mathrm{Na}_{2} \mathrm{HPO}_{4}(0,56 \mathrm{~g})$; $\mathrm{NaC1}(0,85 \mathrm{~g}) ; \mathrm{KH}_{2} \mathrm{PO}_{4}(0,14 \mathrm{~g})$; água destilada q.s.p. $1000 \mathrm{ml}$. Em seguida. foi autoclavada a $120 \circ \mathrm{C}$ durante $20^{2}$ minutos e utilizada para inoculaça no grupo controle (Solucāo C).

II. METODOS - (A) Inoculação: Dos 126 animais, 120 foram inoculados no dia 0 (zero) por via intracerebral, com dnse de $0,03 \mathrm{ml}$, conforme a sequiencia a seguir - Iotes 1 a 4 , inoculađoos com a Soluçāo C;Lates 5 a 8, inoculados com a Soluçăo P1; Lotes 9 a 12, inoculados com a Solução F'2; Lotes 13 a 16, inculados com a Solução P3; Lctes 17 a 20, inoculados com a Soluçāo P4. Os animais pertencentes ao lote 21 não foram inoculados 'f fim dє determinar o nivel de glíccse padrão. (B) Colheita dos cérebros: Os cérabros dos animais foram coletados após sangria branca por punção cardíaca, utilizando-se o método de abertura da calota craniana. Os animais foram sacrificados conforme o esquema a seguir: Dia J (zero), Lote 21; $45^{\circ}$ dia, Lotes 1, 5, 9, 13 e 17; $90^{\circ}$ dia, Lotes 2, 6, 10, 14 e 18; 135\% dia, Lotes 3, 7, 11, 15 e 19; 1800 dia, Lotes 4, 8, 12, 16 e 20. Após a coleta, os cérebros foram colocados em banho de gelo até o início da extracão do carboidrato. (C) Extração e dosagem de glicose: Para extração e dosagem da glicose, seguimos o mélodo utilizado por Alviano et al. 1 descrito em detalhe por Godoy 9.

\section{RESULTADOS}

Após injeç̃o das 21 amastras no cromatógrafo gasoso, obtıvemos as curvas de glicose de cada solução. Aplicando o método já mencionado, chegamos à concentração do referido acuicar, constando seus valores absolutos (em $\mathrm{mm}$ de altura) da tabela 1.

\begin{tabular}{|c|c|c|c|c|c|}
\hline Soluçāo & Dia & $45^{\circ}$ & $90^{\circ}$ & $135^{\circ}$ & $180^{\circ}$ \\
\hline C & & 0,63 & 7,82 & 0,77 & 0,02 \\
\hline $\mathrm{P} 1$ & & 0,60 & 1,90 & 1,05 & 1,82 \\
\hline $\mathbf{P} 2$ & & 3,82 & 3,28 & 2,16 & 3,36 \\
\hline P3 & & 6,40 & 1,14 & 1,81 & 3,90 \\
\hline P4 & & 3,84 & 0,47 & 0,78 & 1,43 \\
\hline
\end{tabular}

Tabela 1 - Valores da glicose em $m m$ de altura. Glicose Padrão $=0,16$.

Transportamos os valores parta papel milimetrado, utilizando $o$ fator de multiplicação 2,5, já que alguns acusaram indices abaixo de $1 \mathrm{~mm}$. O gráfico foi montado comparando as curvas de glıcose das soluçōes P1, P2, P3 e P4 com a solucăo C (Fig. 1). Todas partem da concentraçăo de glicose padrão (tempo 0), obtida a partir do sacrifício doss animaís do lote 21 .

\section{COMENTARIOS}

Mackenzie et al.18 detectaram aumento significativo na concentração de determinadas enzimas em tecido cerebral de camundongos infectados pelo agente do scrapie. Conseqüente acúmulo de material PAS-positivo foi demonstrado no cérebro e medula espinhal dos animais. As enzimas descritas fazem parte do grupo das hidrolases glicosídicas e incluiam a beta-glicuronidase, a $\mathrm{N}$-acetil-beta-D glicosaminidase e a beta-galactosaminidase. Hunter $\mathbf{1 2}$ estudou inúmeras enzimas em tecido nervoso infectado pelo scrapie, dividindo-as em três grupos: (A) enzimas não alteradas em suas funções - neuraminidase, alfa-glicosidase, beta-glicosidase, lipase, fosfolipase A, fos- 
fatase ácida, arilsulfatase A, arilsulfatase B e glicose 6-fosfato desidrogenase; (B) enzimas com atividade aumentada no estágio clínico da doença - catepsina $D$, proteinase ácida, beta-galactosidase e ribonuclease ácida; (C) enzimas com atividade aumentada no periodo de incubação da enfermidade - desoxirribonuclease, hialuronidase, alfa-fucosidase, alfa-manosidase, N-acetil-beta-D glicosaminidase, N-acetil-beta-D galactosaminidase e beta-glicuronidase. As enzimas desoxirribonuclease, N-acetil-beta-D glicosaminidase e N-acetil-beta-D galactosaminidase mostraram ação biológica anormal na 8* semana após a inoculação intracerebral do agente do scrapie, podendo atingir valores duas a três vezes acima dos normais no estágio clínico da moléstia 12 . Kim et al.13, observaram o mesmo fenômeno nos cérebros de hamsters inoculados com tecido nervoso de enfermos com doença de Creutzsfeldt-Jakob (DCJ).

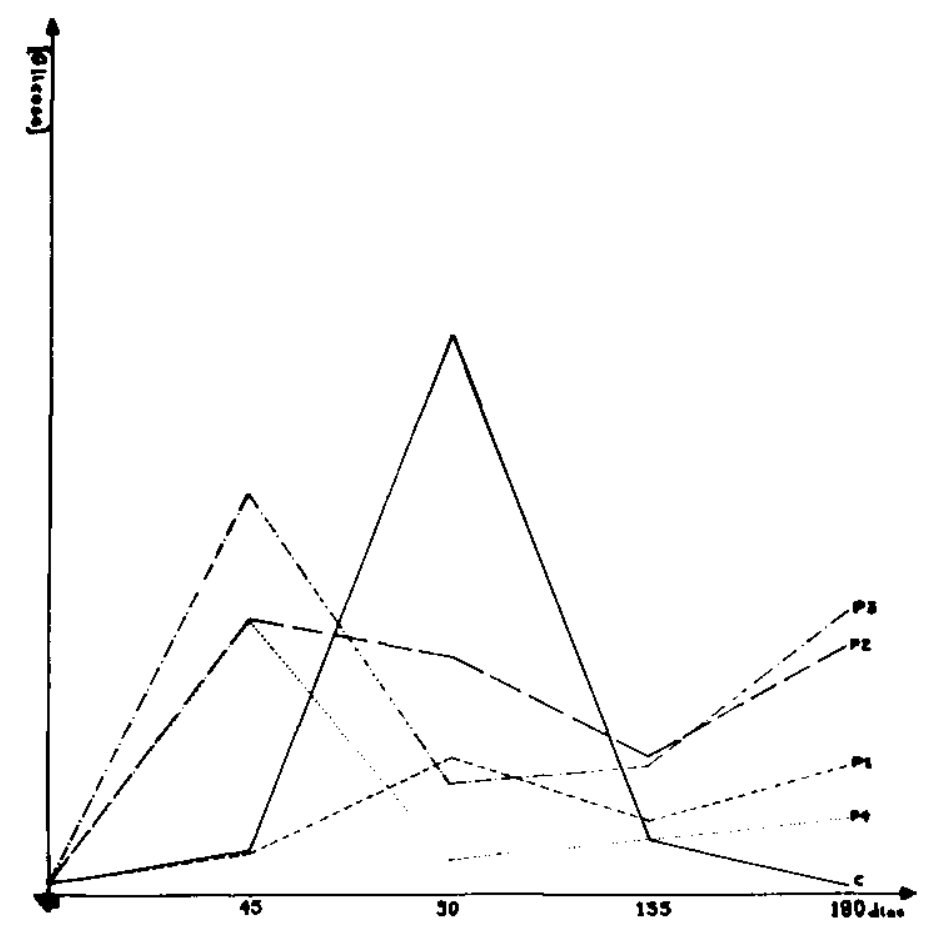

Fig. 1 - Comparaçāo das curvas de glicose das soluçōes P1, P2, $P_{3}$ e $P_{4}$ com a soluctabo $C$.

Com exceção do resultado de alguns poucos estudos 7,16,32, todas as tentativas experimentais de transmitir a ELA não obtiveram êxito. Contudo, segundo Prusiner 26,28, a negatividade nas pesquisas não descarta a participação de um Prion na etiologia da doença, já que o periodo de incubação do scrapie pode ultrapassar o tempo de sobrevida de animais de laboratório 3 e nas encefalopatias espongiformes do homem atinge até 30 anos 5 .

A ligação entre a ELA e Prions advém da variante amiotrófica da DCJ 19,22,29, bastante semelhante à primeira, com sinais de comprometimento dos motoneurônios superior e inferior e preservação do sistema sensitivo. Gibbs e Gajdusek 8 a descreveram, salientando que a transmissão para cobaias não é possível nesses casos e que o aspecto espongiforme, característico, é raro. Em outros estudos é feita alusão aos mesmos resultados $\mathbf{2 2 , 2 9}$. Reforçando as informaçōes mencionadas, é conhecido que em alguns casos de $\mathrm{DCJ}$ não existe vacuolização reconhecivel ao microscópio óptico 26,27 e que esta pode ser observada no neuraxe de pacientes com ELA2,17.

Em nossa experiência, encontramos redução nas concentrações de glicose no cérebro dos camundongos inoculados com as 4 soluções, especialmente no $90^{\circ}$ dia após a ministração do material. 
A presença de um microrganismo, patogênico natural ou por contaminação, também poderia determinar perfil similar. Entretanto, tal possibilidade fica descartada, haja vista que todos os animais apresentaram comportamento normal durante os 6 meses em que foi realizado o estudo.

Alterações metabólicas nos motoneurônios alfa foram notadas apńs secção de nervo periférico, particularmente ligadas aos carboidratos 14 . Aumento na atividade da glicose 6-fosfato desidrogenase é observado durante o fenômeno de cromatólise dos neurônios motores 23. Porém, a ação biológica exacerbada, que se inicia precocemente, retorna ao nivel normal 30 dias após o início do processo 10,15,23,Bo. Em nosso material, o consumo de glicose foi expressivo na faixa do $90^{\circ}$ dia, afastando a hipótese de cromatólise convencional.

Desta forma, concluímos que algum fator desconhecido reduziu os niveis de glicose nas amostras analisadas, fator este veiculado pelo LCR dos pacientes com ELA.

\section{REFERENCIAS}

1. Alviano CS, Souza ET, Esteves MJG, Angluster J, Souza VV - Effect of concanavalin A on the surface of Herpetomonas Samuelpessoai. J Submicrosc Cytol 13:619, 1981.

2. Brownell B, Oppenheimer DR, Hughes JT - The central nervous system in motor neurone disease. J Neurol Neurosurg Psychiat 33:338, 1970.

3. Dickinson AG, Fraser H, Outram GW - Scrapie incubation time can exceed natural lifespan. Nature 256:732, 1975.

4. Emery AEH, Holloway $\mathrm{S}$ - Familial motor neuron diseases. In Howland LP (ed): Human Motor Neuron Diseases. Raven Press, New York, 1982, pg 139.

5. Gajdusek DC - Unconventional viruses and the origin and disappearasice of kuru. Science $197: 943,1977$.

6. Gajdusek DC - Foci of motor neuron disease in high insidence in isolated populations of East Asia and Western Pacific. In Rowland LP (ed): Human Motor Neuron Diseases. Raven Press, New York, 1982, pg 363.

7. Gardashian AM, Khondkarian OA, Bunina TL, Popova LM, Katkin SG - Experimental data on the study of the etiology of amyotrophic lateral sclerosis. Vestn Acad Med Sci 9:80, 1970 .

8. Gibbs CJ Jr, Gajdusek DC - An update on long-texm in vivo studies designed to identify a virus as a cause of ALS, Parkinsonism-Dementia, and Parkinsons' disease. In Rowland LP (ed): Human Motor Neuron Diseases. Raven Press, Nerv York, 1982 , pg 343.

9. Godoy JM - Esclerose Lateral Amiotrófica e Prions. Tese para obtença do título de Livre-Docente em Neurologia. UERJ. Rio de Janeiro, 1958.

10. Häkönen MHA, Kauffman FC - Metabolic alterations in the axotomized superior cervical ganglion of the rat: II. The pentose phosphate pathway. Brain Res 65:141, 1974.

11. Hausmanowa-Petrusewicz I, Borkowska J, Zaremba J - Juvenile motor neuron diseases: the sex influence in benign juvenile pseudodystrophic spinal muscular atrophy. In Rowland LP (ed): Human Motor Neuron Diseases. Raven Press, Nery York, $1982, p g 131$.

12. Hunter GD - Scrapie: a prototype slow infection. J Infect Dis 125:427, 1972.

13. Kim JH, Manuelidis L, Manuelidis EE - Sequential changes in the activity of cerebral glycosidases in experimental Creutzfeldt-Jakob disease of hamsters. $J$ Neuropath Exp Neurol 46:345, 1987.

14. Kreutzberg GW - Changes of coenzyme (TPN) diaphorase and TPN linked dehydrogenase chring axonal reaction of the nerve cell. Nature 199:398, 1963.

15. Kreutzberg GW, Emmert $\mathbf{H}$ - Glucose utilization of motor nuclei during regeneration: a (14C)2-deoxyglucose study. Exp Neurol 70:712, 1980.

16. Lima JMB $\rightarrow$ Contribuiçāo para o estudo da esclerose lateral amiotrófica: aspectos clínico, epidemiológico e virológico. Tese para obtenção do grau de Mestre em Neurologia. UERT. Rio de Janeiro, 1979.

17. Lima JMB - Atrofia cortical na esclerose lateral amiotrófica: contribuição para o estudo da forma demenctal. Tese para obtençăo do grail de Doutor em Neurologia. UFRJ. Rio de Janeiro, 1988.

18. Mackenzie A, Wilson AM, Dennis PF - Further observations on histochemical changes In scraple mouse brain. I Comp Path 78:489, 1968.

19. Matthews WB - Slow infections. In Kennedy PGE, Johnson RT (eds): Infections of the Nervous System. Butterworths, London, 1987, pg 227.

20. Mitsumoto H, Hanson MR, Chad DA - Amyotrophic lateral sclerosis: recent advances in pathogenesis and therapeutic trials. Arch Neurol 45:189, 1988.

21. Müller WK, Hilgenstock F - An uncommon case of amyotrophic latenal sclerosis with isolation of a virns from the CSF. J Neurol 211:11, 1975. 
22. Myrianthopoulos NC, Smith JK - Amyotrophic Iateral sclerosis with progressive dementia. Neurology 12:603, 1962.

23. Nandy K - Histochemical study on chromatolytic neurons. Arch Neurod 18:425, 1968.

24. Patten BM, Engel WK - Phosphate and parathyroid disorders associated with the syndrome of amyotrophic lateral sclerosis. In Rowland LP (ed): Human Motor Neuron Diseases. Faven Press, New York, 1982, pg 181.

25. Pearn JH - Infantile motor neuron disease. In Rowland LP (ed): Human Motor Neuron Discases. Raven Press, New York, 1982, pg 121.

26. Prusiner SB - Novel proteinaceous infectious particles cause scrapie. Science 216:136, 1982.

27. Prusiner SB - Occasional notes: some speculations about Prions, amyloid, ind Alzheimer diselase. Ni: Engl J Med 310:661, 1984.

28. Prusiner Sb - Prions and neurodegenerative diseases. N Engl J Med 317:1571, 1987.

29. Salazar AM, Masters CL, Gajdusek DC, Gibbs CJ Jr - Syndromes of amyotrophic sclerosis and dementia: relation to transmissible Creutzfeldt-Jakob disease. Ann Neurol $14: 17,1983$.

30. Singer $P$, Mehler $S-2$-deoxy(14C) glucose uptake in the rat hypoglossal nucleus after nerve transection. Exp Neurol 69:617, 1980.

31. Tandau R. Bradley WG - Amyotrophic lateral sclerosis: Part 2. Wtiopathogenesis. Ann Neurol 18:419, 1985.

32. Zllber LA, Bajdakova ZL, Gardashian AM, Konovalov NV, Runina TL, Barabadze EM Study of the etiology of amyotrophic lateral sclerosis. Bull WHO 29:449, 1963. 